\title{
Prevalence and predictors of smoking among adolescent schoolchildren in Monastir, Tunisia
}

\author{
S. ElMhamdi, G. Wolfcarius-Khiari, ${ }^{2}$ S. Mhalla, ${ }^{2}$ K. Ben Salem ${ }^{7}$ and S.M. Soltani ${ }^{7}$
}

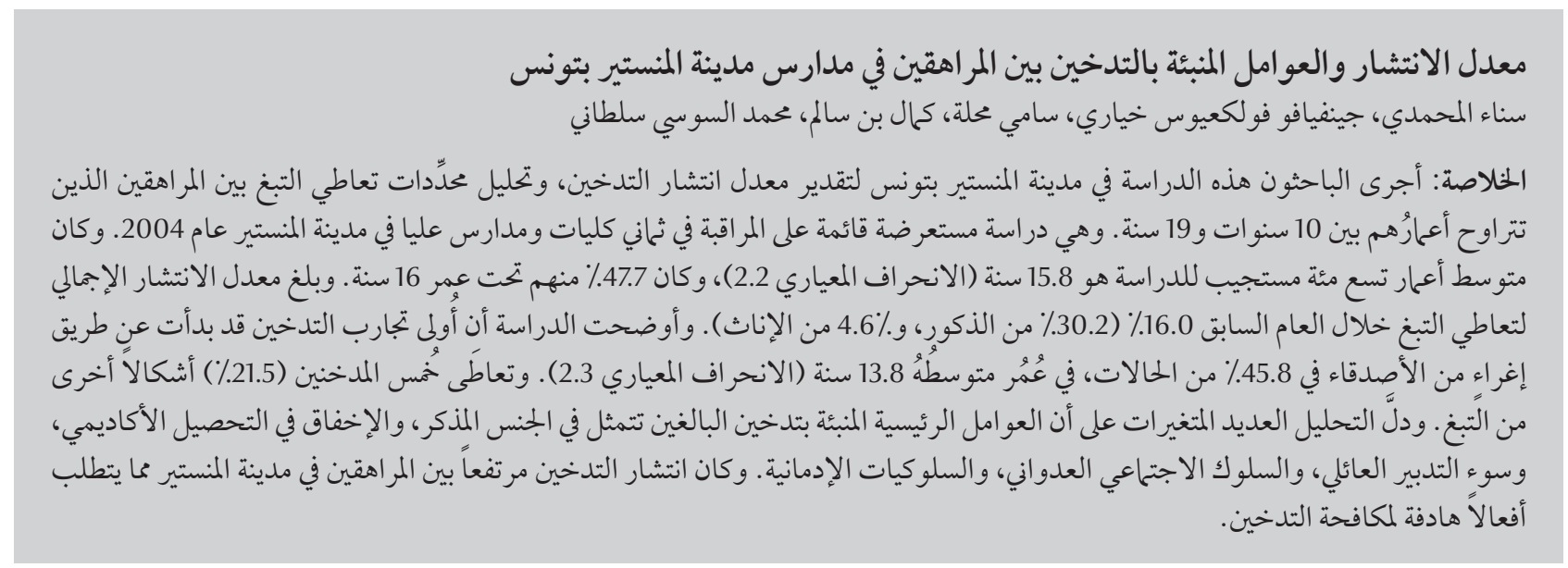

ABSTRACT A study in Monastir, Tunisia estimated the prevalence of smoking and analysed the determinants of tobacco use among adolescents aged 10-19 years. An observational cross-sectional study was performed in the 8 colleges and high schools of Monastir city in 2004. The mean age of the 900 respondents was 15.8 (SD 2.2) years and $47.7 \%$ were aged under 16 years. The overall prevalence of cigarette use during the past year was $16.0 \%$ (30.2\% among males and $4.6 \%$ among females). The first smoking experience was initiated by friends in $45.8 \%$ of cases, at a mean age of 13.8 (SD 2.3) years. One-fifth of smokers (21.5\%) had used other forms of tobacco. In multivariate analysis, male sex, academic failure, poor family management, antisocial behaviour and addictive behaviour were the main predictors of adolescent smoking status. The prevalence of smoking among adolescents in Monastir is high and requires targeted action.

\section{Prévalence et facteurs prédictifs du tabagisme chez les adolescents à Monastir (Tunisie)}

RÉSUMÉ Une étude effectuée à Monastir (Tunisie) a estimé la prévalence du tabagisme et analysé les déterminants de I'utilisation du tabac chez les adolescents âgés de 10 à 19 ans. Une étude transversale d'observation a été conduite dans huit établissements d'enseignement secondaire de la ville de Monastir en 2004. L'âge moyen des 900 répondants était de 15,8 ans (E.T. 2,2) et 47,7\% avaient moins de 16 ans. La prévalence globale de consommation de cigarettes au cours de l'année antérieure était de 16,0 \% (30,2 \% chez les adolescents et 4,6\% chez les adolescentes). La première expérience de consommation de tabac était initiée par des amis dans $45,8 \%$ des cas, à un âge moyen de 13,8 ans (E.T. 2,3). Un cinquième des fumeurs (21,5\%) avait utilisé d'autres formes de tabac. Une analyse multivariée a montré que le sexe masculin, l'échec scolaire, une famille qui ne joue plus son rôle, un comportement antisocial et addictif étaient les principaux facteurs prédictifs du statut tabagique des adolescents. La prévalence du tabagisme chez les adolescents scolarisés à Monastir est élevée et appelle à une action ciblée.

'Department of Preventive Medicine and Epidemiology, University Hospital of Monastir, Monastir, Tunisia (Correspondence to S. El Mhamdi: sanaelmhamdi@yahoo.fr).

${ }^{2}$ Department of Psychiatry, University Hospital of Monastir, Monastir, Tunisia.

Received: 02/09/09; accepted: 31/03/10 


\section{Introduction}

In the face of anti-smoking interventions by policy-makers that aim to reduce the rate of smoking in populations, the tobacco industry often targets adolescents, who are seen as the weakest link in the tobacco epidemic chain [1]. Studies show that almost all smokers initiate cigarette smoking during adolescence, a phase that is influenced by home habits, and the social and school context $[2,3]$. According to the World Health Organization and other studies, the prevalence of smoking among school-age adolescents is high, especially in developing countries, with estimates ranging from $14 \%$ to $29 \%$ [4-7]. These figures for adolescents have serious public health implications [4]. Efforts to prevent uptake of tobacco use by adolescents requires knowledge of the magnitude and the determinants of their smoking habits [2].

A study in Tunisia in 1996 showed that the prevalence of tobacco smoking among adults was high (30.4\% for both sexes) and that the age at which people started smoking appeared to be falling [8]. Thus smoking by adolescents has become a serious concern that demands specific actions such as targeted education campaigns [9]. The success of such interventions requires knowledge of the epidemiological profile of the specific target group. The objective of this study was to estimate the prevalence of smoking and identify the determinants of tobacco use among school adolescents in the city of Monastir.

\section{Methods}

\section{Setting and sampling}

We performed a cross-sectional study in the city of Monastir in Tunisia from 1-21 May 2004. The city had 81296 inhabitants in 2004, of whom 17885 (22\%) were adolescents aged 10-19 years [10]. There were a total of 8 public and private institutions in the city (colleges and high schools) with 240 classes and 7648 students at all levels. Among secondary school adolescents we expected the minimum prevalence of tobacco use to be $10 \%$. The required minimum sample size to determine the prevalence with $95 \%$ confidence limits and $2 \%$ precision was estimated to be 864 adolescents.

A stratified, random sampling method was used to select a representative sample of school adolescents. All 8 public and private schools in Monastir city were included. In each school, classes were randomly selected according to the number at each level. All 1023 adolescents in selected classes were included, of whom 940 were reached at the time of the study and agreed to complete the questionnaire, resulting in a response rate of $91.8 \%$. Incomplete questionnaires were returned by 40 students had and these were excluded. Thus, our final sample comprised 900 students.

\section{Data collection}

Adolescents completed a self-administered questionnaire that was validated in a previous study [11]. It comprised 135 items covering the following domains: sociodemographic characteristics; smoking habits (age of starting smoking, number of cigarettes smoked per day, types of tobacco smoked and environmental tobacco exposure); consumption of toxic substances other than tobacco; family experiences; academic success or failure; addictive and anxious behaviour; aspects of quality of life that could influence smoking habits; and attitudes, perceptions and motivation for smoking

Each domain was explored by various items (yes/no or Likert-type responses) and mean scores were calculated for each domain. After that, the score of each domain was divided into 2 classes (yes/no) according to the cut-offs from previous studies using the same questionnaire [11].

The following operative definitions were used: non-smoker was a student who had never smoked tobacco in any form during his/her lifetime; smoker was a student who ever used cigarettes during the past year; smoking addiction was defined as a Fagerström test score $\geq$ 7 (high nicotine addiction).

The distribution of the questionnaire was made outside examination and revision periods and students completed the questionnaires in their classroom. The completed questionnaires were collected by the researchers.

The survey was approved by the ethics committee of the Ministry of Education. The questionnaire was administered totally anonymously in the classroom. To protect the privacy of participants and to obtain as frank answers as possible, we explained to the students that questionnaires were anonymous. We also explained that participation was voluntary and that not participating would not have any repercussions.

\section{Statistical analysis}

To facilitate the statistical analysis we analysed only the domains of the questionnaire and not the 135 items separately. To identify factors associated with tobacco addiction among adolescents in the city of Monastir, we used Student t-test to compare means and the chi-squared test to compare percentages. A $P$-value $\leq 0.05$ was considered to be statistically significant. Multivariate stepwise logistic regression was used to identify factors independently associated with smoking status. In this model, variables with a univariate test value $\leq 0.25$ were included. The final returned variables were those significant at the level of 5\%. Confidence intervals (CI) at the 95\% level were used for estimation and generalization of different frequencies.

\section{Results}

The mean age of the 900 respondents was 15.8 (SD 2.2) years and $47.7 \%$ were 
under 16 years. There was preponderance of females in the sample (sex ratio $=0.8$ ) and $92.2 \%$ of adolescents were living with both their parents.

A total of 144 students reported that they were smokers, giving a prevalence of smoking among these school adolescents of $16.0 \%$. The prevalence of smoking among men was $30.2 \%$ $(n=121)$ and among women was $4.6 \%$ $(n=23)$. The median number of cigarettes smoked was 7 per day (interquartile range 4-15).

Among smokers there were a significantly higher proportion of males than females ( $84.0 \%$ versus $16.0 \%$ ) $(P<0.01)$ and of those aged $<16$ years than $\geq 16$ years (53.5\% versus $46.5 \%$ ) $(P<0.01)$. However, it did not differ significantly by parent's level of education or parent's smoking status (Table 1)

The mean age of smokers was 15.5 (SD 2.1) years and the mean age at the first smoking experience was 13.8
(SD 2.3) years, with a significant difference according to sex: females were older than males at the first smoking experience (Table 2) $(P<0.01)$. Smoking initiation was motivated by a friend in $45.8 \%$ of cases and by the smoker's family in $10.8 \%$. Among these smokers, $21.5 \%(n=31)$ reported consuming other tobacco products, $8.2 \%$ consumed alcohol and $2.1 \%$ were cannabis users.

In univariate analysis, the domain of academic failure was significantly associated with a greater risk of smoking: the odds increased more than 6-fold with academic failure ( $\mathrm{OR}=6.2,95 \%$ CI: 3.9-9.7). Antisocial and addictive behaviours ( $\mathrm{OR}=2.8,95 \% \mathrm{CI}: 2.3-3.5$ and $\mathrm{OR}=2.3,95 \% \mathrm{CI}$ : $1.9-2.8$ respectively) and favourable attitudes toward alcohol (OR $=3.7,95 \%$ CI: 2.6-5.3) were significantly associated with an increasing smoking risk $(P<0.01)$. We also showed a significant correlation between smoking behaviour and poor family management $(\mathrm{OR}=2.0$, $1.4-2.9)$ and poor quality of life (OR 1.8, 95\% CI: 1.2-2.7) (Table 3). However, family permissiveness and anxious behaviour were not correlated with the smoking status of these adolescents (Table 3).

In multivariate analysis, we included sex; age divided into classes and the other significant risk factors for smoking (as reported in Table 3). In the final model we showed that academic failure significantly increased the risk of smoking after adjustment for others factors $(\mathrm{OR}=3.9,95 \%$ CI: $2.4-6.3)(P<0.01)$. Antisocial behaviour $(\mathrm{OR}=2.2,95 \% \mathrm{CI}$ : 1.2-4.7) and addictive behaviour (OR $=1.7,95 \%$ CI: $1.1-2.8)$ were also still significantly associated with smoking behaviour. This model retained female sex as a protective factor for smoking $(\mathrm{OR}=0.3,95 \%$ CI: $0.2-0.4), P<0.01)$ (Table 4).

\begin{tabular}{|c|c|c|c|c|c|}
\hline \multirow[t]{2}{*}{ Characteristic } & \multicolumn{2}{|c|}{$\begin{array}{c}\text { Total sample } \\
(\boldsymbol{n}=900)\end{array}$} & \multicolumn{2}{|c|}{$\begin{array}{l}\text { Smokers } \\
(n=144)\end{array}$} & \multirow[t]{2}{*}{$P$-value } \\
\hline & No. & $\%$ & No. & $\%$ & \\
\hline \multicolumn{6}{|l|}{ Age (years) } \\
\hline$<16$ & 430 & 47.7 & 77 & 53.5 & \multirow{2}{*}{$<0.01$} \\
\hline$\geq 16$ & 470 & 52.3 & 67 & 46.5 & \\
\hline \multicolumn{6}{|l|}{ Sex } \\
\hline Male & 400 & 44.5 & 121 & 84.0 & \multirow{2}{*}{$<0.01$} \\
\hline Female & 500 & 55.5 & 23 & 16.0 & \\
\hline \multicolumn{6}{|l|}{ Mother's education } \\
\hline School graduate or less & 489 & 54.3 & 69 & 48.0 & \multirow{3}{*}{ NS } \\
\hline College degree & 343 & 38.1 & 58 & 40.0 & \\
\hline Postgraduate education & 68 & 7.6 & 17 & 12.0 & \\
\hline \multicolumn{6}{|l|}{ Father's education } \\
\hline School graduate or less & 289 & 32.1 & 42 & 29.0 & \multirow{3}{*}{ NS } \\
\hline College degree & 416 & 46.2 & 69 & 48.0 & \\
\hline Postgraduate education & 195 & 21.7 & 33 & 23.0 & \\
\hline \multicolumn{6}{|l|}{ Mother smokes } \\
\hline Yes & 234 & 26.0 & 46 & 32.0 & \multirow{2}{*}{ NS } \\
\hline No & 666 & 74.0 & 98 & 68.0 & \\
\hline \multicolumn{6}{|l|}{ Father smokes } \\
\hline Yes & 527 & 58.6 & 75 & 52.0 & \multirow{2}{*}{ NS } \\
\hline No & 373 & 41.4 & 69 & 48.0 & \\
\hline
\end{tabular}

$N S=$ not significant . 


\begin{tabular}{|c|c|c|c|}
\hline \multicolumn{4}{|c|}{$\begin{array}{l}\text { Table } 2 \text { Characteristics of the } 144 \text { school adolescents who were smokers in } \\
\text { Monastir city by sex }\end{array}$} \\
\hline Characteristic & $\begin{array}{c}\text { Males } \\
(n=121)\end{array}$ & $\begin{array}{l}\text { Females } \\
(n=23)\end{array}$ & $P$-value \\
\hline Mean (SD) age of smoker & $15.2(2.3)$ & $16.7(2.0)$ & $<0.01$ \\
\hline $\begin{array}{l}\text { Mean (SD) age at first smoking } \\
\text { experience }\end{array}$ & $13.7(2.3)$ & $14.2(2,2)$ & $<0.01$ \\
\hline $\begin{array}{l}\text { Median no. of cigarettes } \\
\text { smoked/day }\end{array}$ & 6.5 & 7.2 & NS \\
\hline
\end{tabular}

$S D=$ standard deviation; $N S=$ not significant

\section{Discussion}

Our study aimed to estimate the prevalence of tobacco use among adolescents in Monastir city and to assess its correlates. To achieve our objectives we conducted the study on a random sample of college and high-school adolescents using a questionnaire based on validated scores [11]. In order to limit problems of inconclusive or missing answers we clearly explained the objectives of the study to the adolescents. Anonymity was also guaranteed to make students feel more comfortable about responding. However, our results cannot be applied to all young people of the same age.
A new generation of adolescents continue to start using tobacco at younger ages and it is particularly important to prevent tobacco use at this stage of life. Indeed, estimates of the prevalence of smoking among school adolescents range from $9 \%$ to $17.5 \%$ in other developing countries $[12,13]$. In developed countries the rate of tobacco use among adolescents is showing a continual decrease [14]. This decrease is related to effective interventions since the 1980s that target adolescent smoking prevention [15]. In developing countries, including Arab countries, smoking among adolescents has begun to increase alarmingly $[4,7]$.

In Tunisia the prevalence of young smokers is also high: $18.1 \%$ in a national study in 2000 [16]. According

\begin{tabular}{|c|c|c|c|c|c|c|c|}
\hline \multirow[t]{2}{*}{ Risk factor } & \multicolumn{2}{|c|}{ Smokers } & \multicolumn{2}{|c|}{ Non-smokers } & \multirow[t]{2}{*}{ OR } & \multirow[t]{2}{*}{$95 \% \mathrm{Cl}$} & \multirow[t]{2}{*}{$P$-value } \\
\hline & No. & $\%$ & No. & $\%$ & & & \\
\hline Academic failure & & & & & & & $<0.01$ \\
\hline No & 80 & 55.5 & 566 & 74.9 & 1 & - & \\
\hline Yes & 64 & 44.5 & 190 & 25.1 & 6.2 & $3.9-9.7$ & \\
\hline Antisocial behaviour & & & & & & & $<0.01$ \\
\hline No & 96 & 66.6 & 556 & 73.6 & 1 & - & \\
\hline Yes & 48 & 33.4 & 200 & 26.4 & 2.8 & $2.3-3.5$ & \\
\hline Family management & & & & & & & 0.02 \\
\hline Good & 56 & 38.9 & 501 & 66.3 & 1 & - & \\
\hline Poor & 88 & 61.1 & 255 & 33.7 & 2.0 & $1.4-2.9$ & \\
\hline Family commitment & & & & & & & 0.09 \\
\hline Yes & 76 & 52.8 & 479 & 63.4 & 1 & - & \\
\hline No & 68 & 47.2 & 277 & 36.6 & 1.2 & 0.9-1.7 & \\
\hline Quality of life & & & & & & & 0.03 \\
\hline Good & 98 & 68.1 & 604 & 79.9 & 1 & - & \\
\hline Poor & 46 & 31.9 & 152 & 20.1 & 1.8 & $1.2-2.7$ & \\
\hline Attitudes toward alcohol & & & & & & & $<0.01$ \\
\hline Unfavourable & 84 & 58.4 & 533 & 70.5 & 1 & - & \\
\hline Favourable & 60 & 41.6 & 223 & 29.5 & 3.7 & $2.6-5.3$ & \\
\hline Anxious behaviour & & & & & & & 0.1 \\
\hline No & 91 & 63.2 & 546 & 72.3 & 1 & - & \\
\hline Yes & 53 & 36.8 & 210 & 27.7 & 1.0 & $0.8-2.3$ & \\
\hline Addictive behaviour & & & & & & & $<0.01$ \\
\hline No & 46 & 31.9 & 660 & 87.3 & 1 & - & \\
\hline Yes & 98 & 68.1 & 96 & 12.7 & 2.3 & $1.9-2.8$ & \\
\hline
\end{tabular}

$O R=$ odds ratio $; C I=$ confidence interval. 


\begin{tabular}{lccc}
\hline $\begin{array}{l}\text { Table } 4 \text { Risk factors for smoking among school adolescents of Monastir city: } \\
\text { multivariate logistic regression analysis }\end{array}$ & OR & $\mathbf{9 5 \%} \mathbf{C l}$ & $\boldsymbol{P}$-value \\
\hline Risk factor & 0.3 & $0.2-0.4$ & $<0.01$ \\
Sex & 3.9 & $2.4-6.3$ & $<0.01$ \\
Academic failure & 2.2 & $1.2-4.7$ & $<0.01$ \\
Antisocial behaviour & 1.7 & $1.1-2.8$ & 0.03 \\
Addictive behaviour & 1.6 & $1.0-2.7$ & 0.04 \\
Poor family management &
\end{tabular}

$O R=$ odds ratio $; C l=$ confidence interval.

to the Global Youth Tobacco Survey (GYTS) in the Eastern Mediterranean region, this prevalence was rising constantly between 2001 and 2007 [17]. In our study of adolescents from Monastir city, we also found a high prevalence of self-reported smoking (16.0\%). The rates recorded in our country require health care policies that encourage targeted tobacco prevention strategies. If effective actions are not implemented the consequences of the tobacco habit, especially in youth, will be heavy [18]. We also need a description of the determinants of smoking cessation among this particular population of adolescents to improve the effectiveness of tobacco prevention programmes.

According to the literature, tobacco consumption among females varies across different countries/cultures. Although there are societies without appreciable sex differences in tobacco use [19], many studies have found that tobacco use is more common among males than females $[20,21]$. In our study we also found a male predominance in tobacco consumption. This is mainly related to cultural and social taboos against women smoking in Tunisia.

The mean age of first smoking experience was 13.8 (SD 2.3) years in our study. This is younger than in most studies of tobacco use among teenagers [22]. This finding confirms the need for strategies to help young people to avoid starting smoking, for example through school-based programmes for smoking prevention [23].
The use of other tobacco products is frequent among cigarettes users, both male and female [24]. It has been reported that over $60 \%$ of cigarette smokers use other tobacco products [25]. In our study, $21.5 \%$ of the adolescents used other tobacco products. Although this prevalence was lower than found in other studies, it is expected to increase rapidly. Indeed, in the GYTS, the use of other tobacco products besides cigarettes in Tunisian adolescents rose from $8 \%$ to 15\% between 2001 and 2007 [17].

Compared with non-smokers, current smokers also show other addictive behaviours that have been attributed to a lower quality of life and greater life stresses [26]. Affiliation with drugusing peers increases the risk of starting tobacco smoking and the use of illicit substances [27]. Our results are consistent with the literature that indicates that almost half of smokers begin their experience with peers who are smokers. These results highlight the key role of friends in smoking initiation and suggest a need for collective interventions among youth [28]. These prevention strategies should involve not only the students themselves but also the home, school and social environments [29].

Studies with youth groups have documented an association between academic difficulties and cigarette use. Several arguments have been advanced to explain this correlation; the most important suggests that smoking may be a means to compensate for stress due to lower academic achievement [27]. In fact, some studies from both developed and developing countries concluded that academic failure is a predictive factor for early tobacco, alcohol and marijuana use [6,30]. In our study, univariate and multivariate analyses were consistent with those of other studies.

Many strategies can be used to prevent adolescents' tobacco use, such as laws restricting sales of tobacco products to minors. However, the evidence that such laws are effective in preventing initiation of tobacco use by adolescents is limited [31]. Others strategies against adolescents' tobacco smoking are more likely to be effective, such as school-based programmes [32] and media-based tobacco-counter marketing campaigns [33]. We also can use new technologies (Internet/e-mail) that have proven effectiveness in including adolescents in anti-tobacco actions and prevention [34]. Youth who have already started smoking also should be targeted and given specific counselling in order to help them to escape their addiction [33].

\section{Conclusion}

In our study we showed that smoking rates among adolescents remains high in Tunisia and the age of initiation of smoking was under 14 years. These results suggest that greater investment in preventive measures is needed to limit the human and economic impact of the smoking among young people.

\section{Acknowledgements}

Special thanks are due to Dr Zaafrane Ferid (Professor of Psychiatry) for his help in the monitoring of this study, the Ministry of Education for their agreement and help in the implementation of the study and the regional directors of study of schools and colleges for their help and their contribution in this study. 


\section{References}

1. Grimshaw GM, Stanton A. Tobacco cessation interventions for young people. Cochrane Database of Systematic Reviews, 2006, (4):CD003289.

2. DiNapoli PP. Early initiation of tobacco use in adolescent girls: key sociostructural influences. Applied Nursing Research, 2009, 22:126-132.

3. Nilsson $\mathrm{M}$ et al. Adolescent's perceptions and expectations of parental action on children's smoking and snus use; national cross sectional data from three decades. BMC Public Health, 2009, 9:74.

4. Nazary AA et al. Smoking among male medical sciences students in Semnan, Islamic Republic of Iran. Eastern Mediterranean Health Journal, 2010, 16:156-161.

5. Heydari $\mathrm{G}$ et al. Prevalence of smoking among high-school students of Tehran in 2003. Eastern Mediterranean Health Journal, 2007, 13:1017-1021.

6. Abolfotouh MA et al. Health-related lifestyles and risk behaviours among students living in Alexandria University Hostels. Eastern Mediterranean Health Journal, 2007, 13:376-391.

7. Al-Mohamed HI, Amin TT. Pattern and prevalence of smoking among students at King Faisal University, Al Hassa, Saudi Arabia. Eastern Mediterranean Health Journal, 2010, 16:56-64.

8. Fakhfakh $\mathrm{R}$ et al. Tobacco use in Tunisia: behaviour and awareness. Bulletin of the World Health Organization, 2002, 80:350-356.

9. Fakhfakh R, Hsairi M, Achour N. Epidemiology and prevention of tobacco use in Tunisia: a review. Preventive Medicine, 2005, 40:652-657.

10. Demographic health survey in Tunisia 2004. Tunis, National Family and Population Office, 2005.

11. Melki W et al. [Validation of a school children addictive behaviors questionnaire.] Validation d'un questionnaire d'addiction en milieu scolaire. La Tunisie Medicale, 2006, 84:603-606.

12. Sreeramareddy CT et al. Prevalence and correlates of tobacco use amongst junior collegiates in twin cities of western Nepal: a cross-sectional, questionnaire-based survey. BMC Public Health, 2008, 8:97.

13. Mpabulungi L, Muula AS. Tobacco use among high shool students in Kampala, Uganda: questionnaire study. Croatian Medical Journal, 2004, 45:80-83.

14. Rasmussen $M$ et al. Smoking trends in 11-15-year-olds from 1988 to 2006. Ugeskrift for Laeger, 2008, 170:736-739.

15. Murphy-Hoefer $\mathrm{R}$ et al. A review of interventions to reduce tobacco use in colleges and universities. American Journal of Preventive Medicine, 2005, 28:188-200.

16. Fakhfakh $\mathrm{R}$ et al. Trends in tobacco consumption in Tunisia. Eastern Mediterranean Health Journal, 2000, 6:678-686.

17. Warren CW et al. Global youth tobacco surveillance, 20002007. Morbidity and Mortality Weekly Report, 2008, 57(SS01):128.

18. Fakhfakh R et al. [Epidemiology and prevention of smoking in Tunisia: current situation and perspectives.] Epidemiologie et prevention du tabagisme en Tunisie: situation actuelle et perspective. Archives de l'Institut Pasteur de Tunis, 2001, 78:59-67.
19. Alexander J, Alexander P. Gender differences in tobacco use and the commodification of tobacco in Central Borneo. Social Science \& Medicine, 1994, 38:603-608.

20. Edvardsson I, Lendahls L, Håkansson A. When do adolescents become smokers? Annual seven-year population-based follow-up of tobacco habits among 2000 Swedish pupils-an open cohort study. Scandinavian Journal of Primary Health Care, 2009, 27:41-46.

21. Rudatsikira E, Muula AS, Siziya S. Prevalence, correlates of and perceptions toward cigarette smoking among adolescents in South Korea. Indian Journal of Pediatrics, 2009, 76:505-510.

22. Rodrigues ES, Cheik NC, Mayer AF. Level of physical activity and smoking in undergraduate students. Revista de Saude Publica, 2008, 42:672-678.

23. Thomas R, Perera R. School-based programmes for preventing smoking. Cochrane Database of Systematic Reviews, 2006, 3:CD001293.

24. Yang T et al. Smoking patterns and sociodemographic factors associated with tobacco use among Chinese rural male residents: a descriptive analysis. BMC Public Health, 2008, 8:248.

25. Bombard JM et al. Monitoring polytobacco use among adolescents: do cigarette smokers use other forms of tobacco? Nicotine and Tobacco Research, 2008, 10:1581-1589.

26. Okasaka $Y$ et al. Correlation between addictive behaviors and mental health in university students. Psychiatry and Clinical Neurosciences, 2008, 62:84-92.

27. Corona $\mathrm{R}$ et al. Risk and protective factors for tobacco use among 8th- and 10th-grade African American students in Virginia. Preventing Chronic Disease, 2009, 6:A45.

28. De Leeuw RN et al. Relative risks of exposure to different smoking models on the development of nicotine dependence during adolescence: a five-wave longitudinal study. Journal of Adolescent Health, 2009, 45:171-178.

29. Bawazeer AA, Hattab AS, Morales E. First cigarette smoking experience among secondary-school students in Aden, $\mathrm{Re}$ public of Yemen. Eastern Mediterranean Health Journal, 1999, 5:440-449.

30. Bergen HA et al. Perceived academic performance and alcohol, tobacco and marijuana use: longitudinal relationships in young community adolescents. Addictive Behaviors, 2005, 30:1563-1573.

31. Stead LF, Lancaster T. Mass media interventions for preventing smoking in young people. Cochrane Database of Systematic Reviews, 2000, (2):CD001006.

32. Abolfotouh MA et al. Smoking intervention programme for male secondary-school students in south-western Saudi Arabia. Eastern Mediterranean Health Journal, 1997, 3:90-100.

33. Glynn T et al. The globalization of tobacco use: 21 challenges for the 21st century. CA: a Cancer Journal for Clinicians, 2010, 60:50-61.

34. Norman CD et al. Using the internet to assist smoking prevention and cessation in schools: a randomized, controlled trial. Health Psychology, 2008, 27:799-810. 